\title{
An overview of green economics
}

\author{
Richard Lawson
}

The Old School House

Station Road, Congresbury

North Somerset, BS49 5DX

Fax: 01934834165

E-mail: rlawson@gn.apc.org

\begin{abstract}
This paper reviews the foundational axioms, principles, aims and instruments of the system of Green Economics. It ties economics to its ecological foundations, delineates a simple structure for the economy, investigates the relationship between resources, work, wealth and money. Equity is discussed in all its relationships, and capitalism and divergence between the fortunes of rich and poor are considered.

Green economics is a new discipline, and this is therefore an important moment in which to try to find an orientation and to try to produce a sketch map of the field. This paper is an attempt to provide a provisional plan. Its aim is to place the various elements of green economics into relationship with each other rather than to provide a detailed exposition or argument for each point.
\end{abstract}

Keywords: economics; green; ecological; axioms; structure; externalities; resources; equity; guided market.

Reference to this paper should be made as follows: Lawson, R. (2006) 'An overview of green economics', Int. J. Green Economics, Vol. 1, Nos. 1/2, pp.23-36.

Biographical notes: Dr. Richard Lawson is a Family Doctor and Psychiatrist in North Somerset. He is a seasoned environmental and peace campaigner, and is a well-known national speaker on Green issues. He was elected to Woodspring District Council in 1986, and served for six years. He is the author of 'Bills of Health', which shows that about one-fifth of NHS effort is wasted in trying to cure illness caused by non-green policies.

\section{The ecological foundation of economics}

Ecology and economics are closely related both etymologically and philosophically. Eco- signifies home or habitat, -logy refers to study, and -nomy relates to management. Philosophically, they are therefore sister disciplines: understanding must underpin management: therefore ecology must underpin economics.

In this way, green economics is simply bringing economics back to its rightful intellectual grounding. 


\subsection{Ecology}

Ecology is the branch of science that studies the distribution and abundance of living organisms, and the interactions or interrelationship between organisms and their environment. Ecology describes the world in terms of systems - assemblages of interrelated elements constituting a unified whole - rather than in terms of single, linear or isolated events.

\subsection{Economics}

"Economics is the study of how society decides what and how and for whom to produce" (Begg et al., 2003). Economics strives to be a science, whereas the subject matter places economics within the social sciences that study and explain human behaviour. It describes how scarce resources are allocated between competing claims on their use.

Economics' status as a science is subject to debate. Soros (1998) argues that as the subject matter of economics is thought, the thinking applied to the subject matter may affect the outturn of the process which is being considered. Therefore it cannot be classified alongside the more hard-edged sciences of chemistry or physics, where (aside from Heisenberg's Principle) the subject matter is not much affected by the presence of the observer.

\subsection{Ecological economics}

Ecological economics can be defined as the social science of the interaction between the production, consumption and transfer of goods and services by humans, taken in relation to the physical processes of the ecosystems that support life.

Economic science can be subdivided into the positive - descriptive of what flows from given assumptions - and the normative, when it prescribes that a certain action should be taken. Sustainable economics, it is argued here, is decidedly normative.

It is sobering to consider that non-sustainable economics by definition implies a breakdown of the current system at some point in the future. It is perhaps because of this that there is a tendency by some economics writers to degrade the meaning of the term 'sustainable'.

\section{The axiomatic basis of green economics}

I propose that Green Economics is based on three axioms:

1 It is impossible to expand forever into a finite space.

2 It is impossible to take forever from a finite resource.

3 Everything is interconnected.

The effect of applying these axioms to economics should be to harmonise human activities with the processes of nature. Harmonise would mean that the human economic system will be able to nest comfortably within the living ecosystem that surrounds and supports it, with a benign, dynamic, continuous, two-way interaction between one and the other. 


\section{The structure of the economy}

The foundations of any economy are natural resources. These are wrongly regarded as 'inputs' by conventional economics and as an infinite resource to be used and discarded at will with no cost, price or value above that of the current market transaction. Green economics turns this whole structure upside down.

Figure 1 The structure of the economy

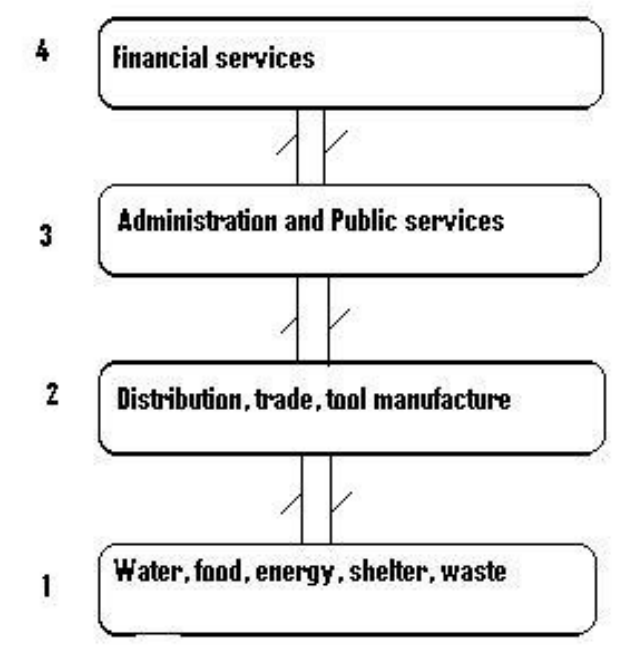

For the purposes of comprehension, in this essay the economy will be divided into four ranks to emphasise the relative positions of the natural world and human economic institutions.

\subsection{The first rank of the economy}

The first rank of the economy relates to producing from our environment the necessities of life, namely:

- water

- food

- energy

- $\quad$ shelter

- $\quad$ safe management of waste products.

This production is the universal basis of all economies, from Robinson Crusoe to New York City. In advanced economies, these processes are hidden and simply assumed to exist; but closer examination shows that the economic basics are everywhere compromised, both in developing and in advanced economies. The water distribution system in the UK is deteriorating; food production is highly demanding in terms of energy and pesticides, while it also erodes the soil, which is the substrate of food 
production; we are excessively dependent on animal protein, which is inefficient in land-use terms, and involves much abuse of animals. Our energy use is simply unsustainable, and is also disrupting the climate; and finally we are poisoning the oceans with waste products that ought properly to be returned to the land as fertiliser.

\section{Land use and carrying capacity}

All of these first-rank activities assume access to, and use of, a certain area of land. This is known as the ecological footprint, although the term as used here must include surface area needed to absorb waste products, which is sometimes left out of consideration. In a free and democratic society this access should be seen as a birthright for every human being. Each human has a notional right to a proportion of the earth's surface. Therefore, anyone holding an area of land should pay rent to the community in recognition of his/her being allowed special enjoyment of that land. This consideration is the basis of the Land (or Site) Value Tax, which is a core green tax, and it also forms the philosophical basis for the Citizen's Income (see below), where the productivity of the land is symbolised by an unconditional income for every citizen.

The corollary of this right of access is the duty to be sure that we do not overburden the land, in accordance with the first and second axioms. Any area of land has a finite carrying capacity - defined as the ability to sustain a certain population of any species. The finite nature of carrying capacity is an incontrovertible ecological fact. The ecological footprint is the land and water area that is required for the material standard of living of a given human population, using prevailing technology. It can be understood as the product of population numbers and consumption patterns, so that 100 people with a more sustainable consumption pattern might have a smaller footprint than 50 people with a careless lifestyle; but even if the entire human population had the most frugal and ecologically sound consumption patterns possible, it would still be the case that there is a limit to the capacity of the planet to carry a human population.

The appropriated carrying capacity is another name for ecological footprint, 'appropriated' signifying that it is claimed, captured or occupied. It reminds us that we appropriate ecological capacity for food, energy, waste absorption, etc. In industrial regions a large part of these first-rank goods are imported (Chambers et al., 2000).

Unfortunately, when these facts are considered in a human context, there is a clash with the human right of any couple to have as many babies as they wish. This clash between libertarian ideals and ecological imperatives belongs more to the realm of politics than economics, but it should be noted that the Green position is that the issue must be resolved through education rather than compulsion, and that a thorough understanding of the realities of population growth needs to be taught in schools.

\subsection{The second rank of the economy}

The second rank of the economy covers the activities of distribution, trade and the manufacture of tools. They imply a societal formation (rather than a single individual in a subsistence situation), and a certain amount of division of labour. 


\subsection{The tertiary rank}

The tertiary rank evolves in a complex society, comprising administration and public services. Public services ensure that adequate amounts of the first-rank items are available to all, in addition to health, education and welfare. It should be noted that human beings are social animals, and that therefore public services are a necessary and natural part of an economy.

\subsection{The quaternary rank}

The quaternary rank, consisting of financial or monetary services, is useful in complex economies. It can be seen from this that green economics turns the approach to the subject on its head. Money is the fourth rank of the economy in green terms, although it is always taken as the starting point of macroeconomics in conventional discussions. This difference underpins the difference between green and conventional economics. To adapt an old saying, food will get you through times of no money better than money will get you through times of no food. This is not to deny the importance of money in economic theory, but it is simply to assert that money is a servant of economic functioning, not the master.

The way in which we gather data to measure the health of an economy is an important determinant of whether money or reality is the basis of economics. Gross Domestic Product is a measure based on finance, which conflates costs, benefits and changes in capital stock. Daly (1992) argues that this is a highly dubious accounting procedure. In preference, green economics would use metrics such as the Index of Sustainable Economic Welfare (Jackson and Marks, 1994), which measures, among other things, environmental conditions, loss of natural capital and social conditions (Ekins, 1992) to reflect more accurately the state of affairs in the real economy. It is noteworthy that in a period when the UK GNP showed steady growth, the ISEW showed a recession.

\section{Money, wealth and resources}

\subsection{Money}

Money is a symbol of value, a symbol that represents the power to obtain real goods and services. Money has no intrinsic value. Its purpose is to serve the smooth running of the economy, and should not be to dominate it.

The huge international trade in money is intrinsically irrational, as it is trade in a symbol, not a commodity or a service. The proposed Tobin Tax (Mahbub ul Haq and Grunberg, 1996) on this trade, set at a fraction of $1 \%$ of transactions to be hypothecated to the poorest regions of the earth, would help to stabilise this trade and would inhibit divergence between rich and poor at the same time.

Theories and practices that treat money as an entity are not sustainable in the long-term as they allow financial value to drift away from the ecological and social realities of life which are things which are classed as 'externalities' in conventional economics. Green economics internalises these realities into monetary or market values 
at every opportunity and uses concepts of fairness and ethics to try to reallocate them more constructively. Conventional economics expects society as a whole to pay for these hidden costs.

Green economics will move towards greater provision of money creation by the community on the basis of ecological or social need, together with the resources and person power available to fulfil that need. Debt and interest are important drivers of economic growth (Hoogendijk, 1991), through the cycle of borrowing to increase productivity. Money has become the greatest source of power in the world. In theory, ultimate power in democracies should lie with the people, but in practice, state power lies with the wealthy, who can buy public opinion by owning newspapers and broadcasting industries (Palast, 2003). This political system is more accurately described as a plutocracy or monetocracy than as a democracy. Green politics would limit the power of individuals and corporations to monopolise the media as part of a healthy economy.

\subsection{Wealth}

Wealth is created from natural resources by work. We take a resource from the environment and act (or work) upon it to increase its utility or value for humans or the environment.

\subsection{Resources}

At its most simple, the resource may be an apple, and the action is that of grasping and eating it. At its most complex, it may comprise the many operations implicated in making a computer, involving science, theory, innovation, design, planning, mining, refining, moulding, assembly, marketing, distribution, support and recycling. Resources are either finite or renewable.

\subsubsection{Finite resources}

Schumacher (1980) pointed out that at least some of the wealth generated by using finite resources must be devoted to helping us to become independent of those finite resources.

Resource taxes internalise the costs of depleting primary resources, and make recycling more economic, both through increasing the cost of primary resources, and, if necessary, through tax breaks for recycling industries.

In the case of finite fuels (coal, oil, gas, uranium), the resource taxes should be hypothecated to energy conservation and the development of renewable energy.

\subsubsection{Renewable resources}

It is one thing to deplete a finite resource, but to destroy renewable resources such as fish stocks, forests and soil is in an entirely different league of thoughtless irrationality - yet conventional economics and politics is providing an environment which allows this to happen with almost no thought or discussion. Green economics carefully regulates their use to ensure that their capacity is maintained and improved. 


\subsection{Throughput of resources and economic growth}

Physically, a sustainable economy that aims to comply with the three axioms will minimise throughput of materials and maximise reuse and recycling of materials. This means moving the model of production from the current linear mode (mine-manufacture-use-dispose) to a new cyclical mode (recover-manufacture-use-reuse-recycle). Both forms require throughput, but in the case of cyclical production the throughput is enormously reduced.

No releases should be permitted that could overwhelm the capability of the biosphere to absorb them, and any persistent toxins must be either not produced or must be sequestered and/or neutralised. Direct regulation rather than taxation applies in this case.

Durability must be in-built into products, instead of the current tendency towards disposability, in order to reduce throughput.

The first and second axioms invalidate the prevailing shibboleth of unconditional economic growth as a measure of the health of an economy, because all economic activity, no matter how cyclical in mode, must involve some throughput (Douthwaite, 1992). It is important however to realise that it is the growth of throughput - that is, the linear process - that makes indefinite economic growth physically impossible, and not necessarily the growth in activity or services per se.

A period of expansion in the green sector of the economy is actually desirable at the present time, as growth could take place in activities connected with the healing, maintenance and development of environmental and social well-being. This green growth would reduce unemployment significantly, at least until the steady-state economy (Daley, 1992) is attained.

\subsection{Taxation: internalising costs}

Conventional economics disregards any values that do not lie in the financial sphere. Profit is all; damage to society or environment is regarded as an 'externality', something which the economist can disregard. Green economics on the other hand demands that these costs be internalised into the product or process by applying a financial value to represent the ecological or social costs of the damage done. Green economics recommends the use of the following instruments:

\subsubsection{Resource taxes}

In order to reduce throughput and increase recycling, a resource tax will be placed on any process that takes finite resources from the environment. This will include fossil fuels, fossil water or minerals.

\subsubsection{The polluter pays principle}

In a Green economy, if a product has an impact on health or on the environment, and if the impact is not sufficiently severe to warrant banning the product, a tax or levy is built into the price to cure the problem that has been caused. This principle applies not only to products and processes with an environmental impact, but also to those with an impact on human health (Lawson, 1996). 


\subsubsection{Producer responsibility}

This simple principle, which underlies the whole juridical process as a matter of course when applied to individual behaviour, is a revolutionary idea to economics. It is assented to in principle by successive UK governments, but they draw back from implementing it, because they fear it would be too difficult (personal communication).

Producer responsibility involves placing a levy on all processes and products, sufficient to pay for:

- the cost of researching any effects the products may have, e.g., on the health of environment or humans, and then, if such effects are found

- the cost of neutralising these effects.

It is easy to see where the government's difficulty lies: it is not a technical problem, but the worry is over the impact on competitiveness, since if not applied simultaneously, the country that applied this measure would find itself at a disadvantage in the marketplace.

This problem has now been elegantly sidestepped by the Simultaneous Policy proposal (Bunzl, 2001). Under this mechanism, political leaders are asked to make pledges to act when an agreed number of competitor leaders have made the same pledge.

\subsubsection{Hypothecation of taxes}

Since green taxes are often applied for a set purpose, it is appropriate that they, in so far as is practical, be applied to remedy the problem that they were applied for in the first place. The logic of this process aids in making the tax acceptable to the taxpayer. For instance, some of the tax on cars and fuel should go to support public transport; a tax on sugar should go to recreate a free NHS dental service; a tax on saturated fats should help to pay the NHS for the cost of preventing and treating heart disease, and so on.

\subsubsection{Positive inducements}

While levies and taxes will be placed on products and processes which harm health or the environment, socially and environmentally beneficial products and processes can be encouraged with tax breaks and other financial advantages.

\subsubsection{Tradeable credits}

One of the disadvantages of the tax instrument is that the rich can continue to pollute and take while the poor simply have to do without. For this reason Tradeable Credits, a form of rationing, could be used. In the case of carbon credits, each citizen will be offered credits for carbon dioxide emissions which they can either use, or place on the market. This is a more equitable and convergent method which can complement the tax instrument. The total amount of credits in circulation can be managed, reduced and modified according to society's needs and balanced with resource issues and ecological health. 


\subsection{Work}

Work and resources create value. Work can be seen as a way of reducing the entropy of (increasing the order in) a system. The work of the home-maker/parent involves a huge amount of re-ordering. The young child is an entropy engine, creating disorder wherever it goes. Parenting involves teaching to distinguish between delight and danger, toy and tool, food and faeces.

In first-rank terms, order is the placing of food and water in the stomach of a person who is hungry and thirsty; creating a distinction between a cold wet environment and a warm dry home; and the positioning of waste matter where it will benefit the vegetable kingdom without contaminating the water supply. Viewed in this way, work is an intrinsic part of our lives.

Good work (that is, work that benefits society and environment) can be stimulated in the absence of money, as evidenced by the Local Exchange Trading Systems (LETS) or Time Bank schemes that are growing in scope and number. In these schemes, money is replaced by credits that are exchanged within the participating community for goods or services (Tibbett, 1997).

Work has been shown to have a beneficial impact on the health of individuals and also of society (Lawson, 1996). Surprisingly, work has been rated close to the top of the list of activities which bring happiness. This is associated with self-esteem, financial reward, time structure and the socialisation associated with work. However, some kinds of work, for instance excessive hours, or undemocratic management structures, may have an adverse effect on health.

Green economics affirms the value of good work (Schumacher, 1980), although we hope that with the increase in the ability of machines to relieve us of routine work, work time will decrease and leisure time will increase.

The manufacture of armaments and explosives should be redefined as a species of antiwork, or work not of benefit to the community and a waste of scarce resources, since their end effect is to increase, not decrease, the entropy in the environment.

Unemployment is intrinsically divergent (see below) in its effects. The present benefit system, which applies $100 \%$ marginal taxation onto benefits at the point when a claimant finds work, acts to perpetuate unemployment. It is irrational to trap people in unemployment and poverty when there is more than enough work that needs to be done in serving, healing and protecting both society and environment.

A sustainable society would provide benefits to those unable to work, help the able-bodied to find good work, and would not withdraw those benefits at the time that the person moves into socially and environmentally useful work. This amounts to a green wage subsidy which could be implemented by allowing companies whose product is certified to be socially and environmentally beneficial to take on new workers, who could retain their benefits. This gradualist approach to the Citizen's Income scheme is set out in Bills of Health (Lawson, 1996). The Citizen's Income is the provision of basic necessities for all from a common fund (Lord, 2003).

One of the virtues of the Citizen's Income is that it acknowledges the economic contribution of the unwaged - parents, homemakers and carers.

Green economics emphasises the importance of the local economy, since it minimises transport impacts, and fosters a sense of community and self-reliance, but it is not the case that it opposes all trade - only inappropriate and wasteful trade. 


\section{Equity, capitalism and divergence}

A sustainable society maximises equity and justice. It aims for optimal distribution of resources within any nation, between nations, and between the present and future generations.

\subsection{Intranational equity}

Capitalism has an intrinsic property of increasing the income differential between rich and poor. Green economics seeks ways of minimising this tendency (see below).

\subsection{International equity}

Sustainability requires convergence between the fortunes of rich and poor countries. 'Third World' Debt Retirement and the Tobin Tax (Mahbub ul Haq and Grunberg, 1996) are available instruments. It should be noted that solar energy will make tropical countries energy rich, and that this, taken with water conservation measures and reafforestation, will help produce economic convergence between developed and less developed countries.

\subsection{Intergenerational equity}

Sharing our wealth with succeeding generations involves the gradual decrease in the discount rate, which is defined in Wikipedia ${ }^{1}$ as follows:

\footnotetext{
"The interest rate used in accounting procedures to determine the present value of future cash flows, i.e., the discounted value of an amount of cash at some future date. The concept of a discount rate is an old one - the future is uncertain, and having something now is worth more than (maybe) having it later. This is reflected in the saying "A bird in the hand is worth two in the bush."”
}

However, the discount principle is also covered by another saying, "Blow you Jack, I'm all right", since the costs that future generations will have to bear, for instance in correcting problems caused by global warming caused by our own use of fossil fuels, has been discounted by economists. Green economics gradually changes this discount rate to reflect costs to future generations of present activities, which is another incentive to develop sustainability.

Although most of the legacies that we leave to our descendants are unwelcome, we can leave three positive legacies to future generations: knowledge, culture and trees. Reafforestation acts as a carbon sink and carries many other positive benefits. Financial incentives can therefore be extended to ecologically sound, community-based reafforestation schemes. In tropical countries, reafforestation should be commenced in coastal areas and gradually extended inland, and must always be carried out on a community, not an industrial, basis. 


\title{
5.4 Capitalism and the market
}

'Capitalism' is a word in need of definition, as it comes with strong political overtones. Wikipedia $^{2}$ gives the following definition:

\begin{abstract}
"Capitalism has not one universally accepted definition, although there are many different definitions of capitalism, but generally refers to one or more of the following:

a system based on one or more of the following economic practices, most of which became institutionalized in Europe between the 16th and 19th centuries, involving the right of individuals and groups of individuals acting as 'artificial legal persons' (corporations) to own and trade private property, especially capital goods such as land and labor, in a relatively free market with the price determined by supply and demand, for profit, and relying on the protection by the state of private property rights and the adjudication by the state or contractually specified third parties of explicit and implicit contractual obligations rather than on feudal protection and obligations.
\end{abstract}

competing theories often meant to justify the private ownership of capital, to explain the operation of such markets, to guide the application or elimination of government regulation of property and markets, to advocate a 'free market', and in some cases meant to advocate elimination of the state itself (the last almost always referred to as anarcho-capitalism rather than capitalism).

a belief in, and arguments for, the advantages of such practices and/or theories."

Neither free market capitalism (termed 'market fundamentalism' by Soros (1998)) nor the command economies of the communist countries have managed to achieve sustainability. They have failed to produce real human happiness and equity. A sustainable system of economic activity should avoid both free market capitalism and the command economy.

A useful distinction may be made between microcapitalism, or entrepreneurialism, and the megacapitalism of the giant corporations, where their sheer scale and overweening influence tends to work against human and environmental values.

Of course, some microcapital enterprises change into megacapital enterprises, and this process can be met with corporation taxes. Ironically, megacapital enterprises (transnational corporations) often pay less taxes, by means of complex and sophisticated tax avoidance schemes. Lang and Hines (1993) propose a 'Site Here To Sell Here' policy to overcome this tendency.

As we have seen earlier, social and environmental impacts of economic activities which are currently classed as externalities will be brought into the price equation through a variety of economic instruments, such as taxes and levies. I propose that this system be termed a guided market.

The guided market values entrepreneurialism, which is an analogue of the tendency of biological species to find and adapt themselves to ecological niches, but subjects the entrepreneur to ecological cost internalisations together with regulations designed to ensure the health of society and environment. 


\subsection{Economic divergence and convergence}

There is a tendency in any capitalist economy, especially in Anglo-Saxon capitalist systems, for the rich to get richer and the poor to get poorer. This tendency might be called divergence and its opposite, convergence. Divergence is intrinsic in capitalism, as capital can grow by being loaned at interest, whereas lack of capital compels people to take out loans which deplete their wealth by requiring interest payments over time. The creditor/debtor relationship is an unequal power relationship. Redistributive taxation attempts to rectify this, but is usually too weak to offset the divergent power of capitalism itself. The Citizen's Income helps to provide a floor for those without capital resources, but green economics faces a challenge in making sure that resource taxes do not put those on low incomes at a disadvantage. Tradeable credits have intrinsically convergent properties.

Divergence, apart from being unethical, is not ecologically sustainable in the long term, as it leads to tensions between social classes, which in turn leads to conflict, which is always environmentally and socially destructive. Recent studies of the causes of human happiness have found that people were happiest in societies where the highest-paid individuals received no more than five times the lowest paid (Layard, 2005). A truly sustainable economy will therefore be convergent.

The debt/interest system is intrinsically divergent in its effects, and must be corrected. Any correction must be gradual and careful, since the income of many vulnerable people, particularly pensioners, is dependent on interest. Reform of the financial system should begin with taxes and levies on financial transactions that are calculated to make money out of money - the Tobin Tax (Mahbub ul Haq and Grunberg, 1996).

\subsection{Green Keynesianism}

Green Keynesianism could smooth out the amplitude of the variations on the economic cycle by using money raised by the state (or community, where appropriate) to stimulate good work during times of economic recession. Good work is work that is of benefit to society or the environment.

Far from being the self-equilibrating system that its devotees assume, the free-market economy is inherently unstable, as evidenced by the boom-bust cycles.

\section{Globalisation}

The globalisation of trade spearheaded by the World Trade Organization (WTO), and resulting in the Global Agreement on Trade in Services, is an attempt to free commercial enterprises from all environmental, social and moral constraints. Peter Sutherland, former Director General of the General Agreement on Tariffs and Trade (GATT), opined that "Government should interfere with the conduct of trade as little as possible, ${ }^{3}$ and Martin Khor, director of the Third World Network, states that globalisation is driven by a set of values that directly contradicts and undermines the "sustainable development paradigm" (Kohr, 2001). As presently set up, globalisation is incompatible with green economics, and large corporations need to be subject to environmental and social legislation. Ultimately, globalisation represents the victory of business over policy, since the corporations have more wealth and power than many governments. The power of the 
corporations must be limited by new policies designed for that purpose (Lang and Hines, 1993). They also have unconscionable power over politicians since political parties are to a significant extent funded by business. For this reason, political parties ought to be funded by the state on the basis of votes received, and donations by business interests must be made illegal. New trade globalisation treaties are needed (Woodin and Lucas, 2004) that will reflect the ecological imperatives that should condition economics.

\section{Conclusion}

To create a sustainable economy is not technically difficult. Indeed, it is far easier than coping with the social and environmental difficulties that will flow from continuing conventional economics. The problem arises in summoning the political will to enable meaningful changes to be made in time to prevent irreversible damage to society and environment.

\section{References}

Begg, D., Fischer, S. and Dornbusch, R. (2003) Economics, 7th ed., McGraw Hill.

Bunzl, J. (2001) The Simultaneous Policy, London: New European Publications, ISBN 0-1872410-15-4.

Chambers, N., Simmons, C. and Wackernagel, M. (2000) Sharing Natures Interest, Ecological Footprints, Earthscan.

Daly, H.E. (1992) Steady State Economics, Earthscan.

Deffeyes, K. (2003) Hubbert's Peak: The Impending World Oil Shortage, Princeton University Press.

Douthwaite, R. (1992) The Growth Illusion, Dublin: Lilliput Press.

Ekins, P. (1992) Wealth Beyond Measure, Gaia Books.

Hoogendijk, W. (1991) The Economic Revolution, Green Print.

Jackson, T. and Marks, N. (1994) 'Measuring sustainable economic welfare - a pilot', Insec 1950-1990, Stockholm Environment Institute, Stockholm.

Kohr, M. (2001) Globalisation and the Crisis of Sustainable Development, Penang, Malaysia.

Lang, T. and Hines, C. (1993) The New Protectionism, London: Earthscan.

Lawson, R. (1996) Bills of Health, Radcliffe Medical Press.

Layard, R. (2005) Happiness, London: Penguin.

Lord, C. (2003) A Citizen's Income, Jon Carpenter Books.

Mahbub ul Haq, K.I. and Grunberg I. (Eds.) (1996) The Tobin Tax: Coping with Financial Volatility, New York, London: Oxford University Press.

Palast, G. (2003) The Best Democracy Money Can Buy, Robinson.

Schumacher, E.F. (1973) Small is Beautiful, London: Abacus.

Schumacher, E.F. (1980) Good Work, London: Abacus.

Soros, G. (1998) The Crisis of Global Capitalism, Little Brown and Co.

Tibbett, R. (1997) 'Alternative currencies: a challenge to globalisation?', New Political Economy, Vol. 2, No. 9, pp.127-133.

Woodin, M. and Lucas, C. (2004) Green Alternatives to Globalisation, Pluto Press. 


\section{Notes}

1 http://en.wikipedia.org/wiki

2 http://en.wikipedia.org/wiki/Capitalism

3 Speech in New York, 3 March 1994 